\title{
Alfred et Lucie DREYFUS, "Écris-moi souvent, écris-moi
} longuement...

Édition établie par Vincent Duclert ; Avant-propos de Michelle PERROT, Paris, Mille et Une Nuits, 2005, 570 pages

\section{Florence Rochefort}

\section{(e) OpenEdition}

\section{Journals}

Édition électronique

URL : http://journals.openedition.org/clio/9520

DOI : $10.4000 /$ clio. 9520

ISSN : 1777-5299

Éditeur

Belin

Édition imprimée

Date de publication : 15 décembre 2009

Pagination : 285-287

ISSN : 1252-7017

Référence électronique

Florence Rochefort, «Alfred et Lucie DREYFus, "Écris-moi souvent, écris-moi longuement... », Clio. Histoire, femmes et sociétés [En ligne], 30 | 2009, mis en ligne le 01 février 2010, consulté le 21 septembre 2020. URL : http://journals.openedition.org/clio/9520 ; DOI : https://doi.org/10.4000/clio.9520

Ce document a été généré automatiquement le 21 septembre 2020.

Tous droits réservés 


\section{Alfred et Lucie DREYFUS, "Écris-moi souvent, écris-moi longuement...}

Édition établie par Vincent Duclert; Avant-propos de Michelle PERROT, Paris, Mille et Une Nuits, 2005, 570 pages

Florence Rochefort

\section{RÉFÉRENCE}

Alfred et Lucie DREYFUS, "Écris-moi souvent, écris-moi longuement..., Édition établie par Vincent Duclert ; Avant-propos de Michelle PERROT, Paris, Mille et Une Nuits, 2005, 570 pages.

1 On doit à Vincent Duclert, éminent spécialiste de l'affaire Dreyfus et biographe d'Alfred Dreyfus, cette première édition minutieuse de la correspondance croisée des époux Dreyfus pendant la captivité du capitaine entre 1894 et 1899, à Paris, à l'île de Ré puis à l'île du Diable en Guyane, et enfin à Rennes. L'ouvrage est introduit par Michelle Perrot et par Vincent Duclert qui fournit aussi pour chaque période de très précises introductions sur le déroulement de l'Affaire et les conditions épouvantables de détention d'Alfred, notamment en Guyane où, à une justice militaire d'exception, répondait un traitement exceptionnellement dur. Sa postface est consacrée plus particulièrement à Lucie et c'est une des originalités du livre. Des annexes (chronologie des faits et des commémorations, bibliographie, sources) complètent l'appareil critique. Les présentations donnent déjà, à elles seules, un intérêt historique indéniable à l'ouvrage et nous permettent de saisir tout l'intérêt de l'échange épistolaire. La lecture émouvante des lettres, souvent répétitives - et pour cause - nous immerge dans la profonde et longue souffrance des principaux protagonistes de l'Affaire. Elle nous permet aussi de saisir les ressorts de leur capacité de résistance.

2 Aux yeux du brillant officier patriote qu'est Alfred Dreyfus, le fait être accusé de haute trahison est la pire des infamies, le plus grand déshonneur possible. Sans information sur ce qui se trame à son propos, publiquement dégradé, il est souvent en proie à la 
tentation de mettre fin à ses jours et Lucie est « le seul fil qui [le] rattache à la vie ». La correspondance apparaît alors comme une pièce maîtresse de l'Affaire, si l'on se place aussi du côté de l'histoire de l'individu Dreyfus lui-même, ce "héros méconnu». Certaines lettres d'Alfred à Lucie, déchirantes de sincérité, ont été d'ailleurs publiées par Joseph Reinach dès 1898 comme preuves irréfutables de son innocence (Lettres d'un innocent) ; celles de Lucie, en revanche, sont restées pour la plupart inédites, quelquesunes interceptées par le ministère ne sont jamais parvenues à leur destinataire et d'autres, publiées en partie, ont été coupées par la famille, en particulier les passages les plus enflammés. Or c'est bien un des intérêts du livre que de mettre en valeur la force de l'amour entre les époux Dreyfus, transcendé par les circonstances tragiques. La censure, le recopiage des lettres par l'administration pénitentiaire et la peur, évacuent du propos épistolaire presque tout l'événementiel de l'Affaire. Ces lettres ne disent rien sur les enjeux politiques ou sur l'antisémitisme, pour ne conserver que l'échange affectif qui permet au couple de tenir bon dans cet «effroyable cauchemar » et de rester tendu vers la nécessité absolue de sauver l'honneur bafoué de Dreyfus en obtenant sa réhabilitation.

Celle qui n'a jamais douté un instant de l'innocence de son mari, est née en 1869. Elle appartient à une famille de la bourgeoisie juive, les Hadamard, originaire de Lorraine. Très épris l'un de l'autre, les jeunes mariés n'ont partagé que « cinq ans de bonheur absolu », quand le jeune capitaine est brutalement arrêté et mis au secret sans plus d'explication. Rien ne préparait cette jeune femme de 24 ans, mère de deux enfants en bas âge, à affronter un complot fomenté au sein d'une Armée vénérée par son milieu, à supporter l'angoisse, le déshonneur, la séparation, les perquisitions répétées et le harcèlement des militaires et des antidreyfusards contre son mari et contre elle-même. Vincent Duclert rappelle que l'acharnement pénitentiaire contre Alfred relevait d'une volonté militaro-policière de provoquer sa mort en détention. Lucie, fortement soutenue par sa famille, mène sans faillir sa tâche de soutien psychologique auprès d'Alfred - sur l'île du Diable elle est la seule autorisée à lui écrire - et auprès de ses enfants à qui elle cache la vérité et dont elle donne très régulièrement des nouvelles à Alfred. La correspondance ne rend pas compte de son rôle indéniable dans la mobilisation des dreyfusards, aux côtés de Mathieu Dreyfus, ni de l'hommage que lui rendent notamment les femmes républicaines et les féministes dreyfusardes - en particulier du journal La Fronde - évoquées dans la postface. S'y lisent aisément, en revanche, la farouche volonté de partager le sort de son époux et de le rejoindre en déportation, ainsi que son souci constant de stimuler sa capacité de résistance et de faire respecter, en vain, ses droits de détenu. Leur idéal commun de justice et de vérité ne fait aucun doute. Plus étonnante est la similitude de leur style épistolaire qui révèle une proximité annonciatrice d'une modernité conjugale à venir, loin des modèles différentialistes de genre de l'époque et de l'argumentaire républicain majoritaire contre les droits des femmes.

Dans son vibrant avant-propos, Michelle Perrot souligne combien cette "édition paritaire » met en valeur le rôle de Lucie Dreyfus auprès de son époux, tous deux portés par un "désir éperdu d'héroïsme salvateur». Les termes mêmes d'héroïsme, de martyre, d'honneur, reviennent en effet régulièrement sous la plume de l'un comme de l'autre. Ce n'est pas seulement Lucie qui loue le courage héroïque d'Alfred, c'est aussi lui qui puise sa détermination à ne pas sombrer dans la folie dans son admiration pour l'héroïsme de Lucie. Pour Vincent Duclert, il ne fait pas de doute que Lucie, par son courage, son sang-froid, sa lucidité et sa combativité, incarne une « héroïne moderne ». 
Il nous invite à mieux la découvrir et amorce ainsi une nouvelle approche de l'Affaire Dreyfus qui, sans rien abandonner du politique, tient compte à la fois des individus, des émotions et de l'apport de l'histoire des femmes et du genre. 